\title{
Diabetic Emergencies: Blood Glucose Crisis in Type-1 DM
}

\author{
Authors \\ Dr R.Sowmya*1, Dr C. Nithish ${ }^{1}$, Dr Ranga Bhanu Prasad ${ }^{2}$, Dr Harisa Kounain ${ }^{1}$ \\ ${ }^{1}$ Department of Clinical Pharmacy Practice, Chalmeda Ananda Rao Institute of Medical Sciences \& \\ Vaageswari College of Pharmacy, Karimnagar, Telangana, INDIA \\ ${ }^{2}$ Department of Clinical Pharmacy Practice, BBR Superspecality Hospital \& Sri Indu Institute of Pharmacy, \\ Hyderabad, Telangana, INDIA \\ Corresponding Author \\ Email: sowmya.reguri09@gmail.com
}

\section{Introduction}

Type 1 diabetes is an autoimmune disorder afflicting millions of people worldwide. Once diagnosed, patients require lifelong insulin treatment and can experience numerous diseaseassociated complications. Type 1 diabetes is generally thought to be precipitated by an immune-associated, if not directly immunemediated, destruction of insulin-producing pancreatic $\beta$ cells ${ }^{[1,2]}$

Type 1 diabetes develops as a consequence of a combination of genetic predisposition, largely unknown environmental factors, and stochastic events, its incidence has increased drastically over the last two decades, especially in children less than five years old ${ }^{[3]}$. Those under the age of 18 are most often afflicted ${ }^{[4]}$, but an equal number of adults over 18 are thought to develop the disease, although incidence in older people, it is not considered as serious event in the clinical world, but it has to be considered as per the current scenario.

Type 1 diabetes was largely considered a disorder in children and adolescents, but this opinion has changed over the past decade, so that age at symptomatic onset is no longer a restricting factor [5].

Despite of providing insulin exogenously, hypoglycemia is the major issue in Diabetes millets.

Signs that your blood sugar is too low may include: Racing pulse, Feeling incredibly hungry, Cold sweats, Headache, Shivering, Feeling restless, Nervous or Anxious, Difficulty in concentration, Confusion. These symptoms do not occur all at once. The signs of hypoglycemia not only depend on the blood sugar level, but also vary from person to person. People who have severe hypoglycemia may feel very drowsy and confused, and might even become unconscious. If this happens, someone else can inject the hormone glucagon.

Three major aspects that contribute to the high frequency of hypoglycemia in type 1 diabetes:-

I. Firstly, the loss of $\beta$-cell insulin secretion and/(thus) the need for exogenous insulin therapy mean that hypoglycemia is more 
likely to develop because of unregulated and sustained hyperinsulinemia.

II. Secondly, within 5 years of disease diagnosis, almost all individuals with type 1 diabetes fail to generate an adequate glucagon response to hypoglycemia ${ }^{[7]}$. Glucagon is the principal rapid-acting counter regulatory hormone, and the portal insulin-to-glucagon ratio is the major determinant of hepatic glucose production. Reduced or absent glucagon release results in a marked impairment of glucose recovery from hypoglycemia ${ }^{[8]}$. A number of intra- and extra-pancreatic factors are thought to contribute to this defect.

Briefly, a failure in local regulation of $\beta$ - to $\alpha$ cell signaling by insulin, zinc, and possibly the neurotransmitter $\gamma$-amino butyric acid (GABA) during hypoglycemia probably play the dominant role in the genesis of this defect, particularly as it seems to track with the progressive loss of $\beta$-cell function [9]. However, recent data suggest that the inhibitory effect of exogenous insulin on $\alpha$ cell glucagon release is in part mediated at the level of the ventromedial hypothalamus $(\mathrm{VMH})^{[10]}$. Thus, the loss of glucagon response to insulin-induced hypoglycemia in C-peptide-deficient type 1 diabetic patients may to be due to the simultaneous increase in insulin levels both within the islet and the VMH. In addition, evidence exists of a local intra-islet sympathetic neuropathy ${ }^{[11]}$, which may contribute in part to impaired glucagon release during hypoglycemia. Again, species differences in islet substructure in rodents limit our translation of these findings to human physiology, but the recognition that a number of defects may contribute to the loss of $\alpha$-cell glucagon secretion during hypoglycemia opens up the possibility of novel therapeutic approaches, such as stimulation of central nervous system (CNS) sensing mechanisms. The selective inability of the $\alpha$-cell to respond appropriately to a hypoglycemic challenge is a hallmark of type
$1^{[8]}$ and long-duration type 2 diabetes ${ }^{[12]}$, which remains poorly understood.

III. Thirdly, the major defect in the counterregulatory response to hypoglycemia in diabetes is a reduced autonomic response. This affects the majority of individuals with type 1 diabetes by 10 years disease duration [7]. Hypoglycemia normally leads to activation of the autonomic nervous system resulting in increased hepatic glucose production and reduced glucose uptake in peripheral tissues. In liver stimulation, sympathetic nervous system activation increases both glycogenolysis and gluconeogenesis; the latter via a simultaneous increase in the delivery of gluconeogenic substrates and free fatty acids ${ }^{[13]}$. The autonomic response is closely associated with the generation of a symptomatic response to hypoglycemia and, as such, when this response becomes impaired there is usually reduced awareness of hypoglycemia as well as a reduction in catecholamine release. This association means the autonomic response to hypoglycemia is critically important in individuals with type 1 diabetes. As will be discussed later in this review, a defective autonomic counter-regulatory response results primarily from prior exposure to hypoglycemia ${ }^{[14]}$, a situation that occurs most frequently during intensive insulin therapy. This sets up a vicious cycle whereby hypoglycemia increases the likelihood of subsequent hypoglycemia.

\section{Description}

\section{Case I}

A 26 year old male patient has complaints of vomiting, increased urine frequency, and giddiness RBS found to be $60 \mathrm{mg} / \mathrm{dl}$. Known history of type I DM since 3years and on inj.lantus of 30U, HBA1C found to be 14.2 it indicates that the person is with diabetic and with the poor control. USG reveals that the increased echo-texture of the bilateral kidneys. Urine 
analysis reveals that the person is with both glycosuria and ketonuria $3.9 \mathrm{mmol} / \mathrm{lit}$. To normalize the patient blood glucose level and decrease the glycosuria and ketonuria the patient kept on inj.HAI of $10 \mathrm{U}$ in 5\% Dextrose normal saline for a continuous IV infusion @ $12 \mathrm{drops} / \mathrm{min}$ and with a hourly GRBS charting. As soon as the patient reached the GRBS level of $160 \mathrm{mg} / \mathrm{dl}$ the insulin infusion was disconnected. Maintenance of the blood glucose levels later done according to the sliding scale and after 4days the patient shifted from the inj.HAI to inj.lantus and is of $20 \mathrm{U}$ dose, suggested with a strict diabetic diet and frequent blood glucose level monitoring. Detailed explanation of first aid management for hypoglycemia. As soon as the first aid in progress immediate consultation with the physician is mandatory.

\section{Case II}

A 27years old male presenting with the complaints of generalized body pains with increased frequency of micturation and thirst since a week, and diffuse type of abdominal pain past three days. RBS found to be $56 \mathrm{mg} / \mathrm{dl}$, HBA1C found to be 16.0 it refers to the diabetic with poor control. CUE reveals positive for glycosuria and ketonuria was found to be $3.9 \mathrm{mmol} / \mathrm{lit}$. USG found to be normal. Initially patient treated with the 5\%dextrose solution as IV flush and then inj.HAI of subcutaneous route of admission according to the sliding scale. And later it has been standardized with the inj.HAI of 10U BD and the blood glucose levels were asked to monitor of FBS, PPBS till discharge. Patient counseled in regard of the strict diabetic control with the diet, exercise, brisk walking for about 3040 minutes every day. Patient was asked to attend for a review after 15days and all this blood glucose levels were found to be normal.

\section{Case III}

A 14years female has been hospitalized with the complaints of vomiting of 5-6episodes, missed the morning and evening dose of previous day, with a known complaints of type I DM since 3years. Laboratory findings shows that the HBA1C is 12.7 which falls under the criteria of diabetic with poor control and presence of glycosuria, and ketonuria is $16 \mathrm{mmol} /$ lit, the RBS reveals $46 \mathrm{mg} / \mathrm{dl}$. Patient was on HAI with 5\% DNS infusion over 24hours with a hourly GRBS charting, and $1 \mathrm{ml} / \mathrm{hr}$ rate of infusion for 4days. Of the GRBS is found to be less than $70 \mathrm{mg} / \mathrm{dl}$ the disconnect the infusion. Patient was explained and counseled in regard of the administration technique and importance of the dose and diet chart, by the clinical pharmacist. Asked for a review after a week. The blood glucose levels and CUE were found to be normal.

\section{Discussion}

\section{Case I}

Diabetes is a state of raised glucose levels of blood, in due process it treated with the antidiabetic drugs, which has a complication of the hypoglycemia i.e., decreased blood glucose levels than that of the normal range. On such a prolonged state it may leads to the neurologic complications like vertigo, unconsciousness, coma, etc, ${ }^{15}$ Reason for hypoglycemia may multi drug usage and other changes in the physiological conditions like insulinoma, dietary modifications. But in this case it is so because of the improper diet management and with a standard insulin administration from exogenous sources. In the due course of the regular patient counseling it has been identified that the patient has skipped the meal and is on insulin injection which is the major cause for the hypoglycemia as reported. Even on the insulin therapy the patient was still with a poor control of the diabetes, can be confirmed by the HBA1C levels. ${ }^{6}$ Patient was counseled about the diabetes and the other diet chart according to the WHO guidelines and explained the technique of the insulin injection intake through the subcutaneous route. ${ }^{16}$ 


\section{Case II}

Patients on type I diabetes on intensive insulin therapy are at high risk of hypoglycemia, the incidence rate ranges from 1.0-1.7episodes per patient per year. Patients with diabetic history of more than 15years will be ranging more as the year increases on. ${ }^{17}$ Patients on insulin have a high chance of hypoglycemic events at the night of $50 \%$. Frequent hypoglycemic events have shown the decreased cognitive performance. ${ }^{18}$ Giddiness associated with the generalized body pain are the presenting complaints and on admission and the RBS was found to be $56 \mathrm{mg} / \mathrm{dl}$. And further untreated of the hypoglycemic condition may leads to the vertigo, unconsciousness and for the immediate recovery of the patient, was on an injection i.e., IV bolus of the 5\%dextorse has been injected and the RBS found to be of $89 \mathrm{mg} / \mathrm{dl}$ and later on the patient was with the insulin therapy with the ideal diabetic diet to prevent further increase in the frequency of the hypoglycemic events.

\section{Case III}

A common knowledge of the insulin cause the hypoglycemia is a well known phenomenon to every one. Mechanisms that cause the hypoglycemia, intrinsic insulin release, decrease of the injected insulin clearance, increased insulin sensitivity and the inhibition of the gluconeogenesis. We are reporting a case of the insulin induced hypoglycemia because of the improper administration techniques and the poor knowledge in regard of the usage of the insulin pens. Here comes the role of the clinical pharmacist in educating the patient in regard of the usage of the insulin pens, route of administration. Lack of the knowledge in the frequency, dosage regimen, and the most important one to manage the hypoglycemic events for the first aid caution. Were all done by the clinical pharmacist in the part of the job. Educating the patient to a extent in regard of the management of the diabetes and its associated risk factors.

\section{Conclusion}

Hypoglycemia on prolonged duration, and or on repeated acts leads to the severe complications, and its cause must be intensively sought. Finding the cause in the diabetic patient is usually straightforward. Patients with insulin especially in the case of TYPE I DM have a high chance of hypoglycemic events.

By this case series we can strongly explain the different mechanisms that leading to the hypoglycemia in the diabetic patients and their management for first aid through the patient counseling in due regard of the patient condition for better patient quality of life.

Keyords: Type 1 DM, Hypoglycemia, Insulin, Glycosuria, Ketonuria, Fasting Blood Glucose (FBS), Postprandial Blood Glucose (PPBS)

Acknowledgement: I express my gratitude to my parents who are the back bone of my success

\section{References}

1. Todd JA. Etiology of type 1 diabetes. Immunity. 2010;32:457-67.

2. Bluestone JA, Herold K, Eisenbarth G. Genetics, pathogenesis and clinical interventions in type 1 diabetes. Nature. 2010;464:1293-300.

3. Harjutsalo V, Sjoberg L, Tuomilehto J. Time trends in the incidence of type 1 diabetes in Finnish children: a cohort study. Lancet. 2008;371:1777-1782.

4. Lorenzen T, Pociot F, Hougaard P, Nerup J. Long-term risk of IDDM in first-degree relatives of patients with IDDM. Diabetology. 1994;37:321-327.

5. Leslie RD. Predicting adult-onset autoimmune diabetes: clarity from complexity. Diabetes. 2010;59:330-31.

6. Hyperglycemia and hypoglycemia in type 1 diabetes-Cologne, Germany: Institute for Quality and Efficiency in Health Care (IQWiG); 2006-Created: May 29，2007; 
Last Update: June 29, 2017; Next update: 2020.

7. McCrimmon R. The mechanisms that underlie glucose sensing during hypoglycaemia in diabetes. Diabet Med 2008;25:513-522

8. Gerich JE, Langlois M, Noacco C, Karam $\mathrm{JH}$, Forsham PH. Lack of glucagon response to hypoglycemia in diabetes: evidence for an intrinsic pancreatic alpha cell defect. Science 1973;182:171-173

9. Fukuda M, Tanaka A, Tahara Y, Ikegami H, Yamamoto Y, Kumahara Y, Shima K. Correlation between minimal secretory capacity of pancreatic beta-cells and stability of diabetic control. Diabetes 1988;37:81-88

10. Paranjape SA, Chan O, Zhu W, Horblitt AM, McNay EC, Cresswell JA, Bogan JS, McCrimmon RJ, Sherwin RS. Influence of insulin in the ventromedial hypothalamus on pancreatic glucagon secretion in vivo. Diabetes 2010;59:1521-1527

11. Mundinger TO, Mei Q, Figlewicz DP, Lernmark A, Taborsky GJ Jr. Impaired glucagon response to sympathetic nerve stimulation in the BB diabetic rat: effect of early sympathetic islet neuropathy. Am J Physiol Endocrinol Metab 2003;285: E1047-E1054

12. Segel SA, Paramore DS, Cryer PE. Hypoglycemia-associated autonomic failure in advanced type 2 diabetes. Diabetes 2002;51:724-733

13. Fanelli CG, De Feo P, Porcellati F, Perriello G, Torlone E, Santeusanio F, Brunetti P, Bolli GB. Adrenergic mechanisms contribute to the late phase of hypoglycemic glucose counterregulation in humans by stimulating lipolysis. J Clin Invest 1992;89:2005-2013
14. Heller SR, Cryer PE. Reduced neuroendocrine and symptomatic responses to subsequent hypoglycemia after 1 episode of hypoglycemia in nondiabetic humans. Diabetes 1991;40:223-226

15. Service FJ, McMahon MM, o'Brien PC, Ballard DJ. Functioning insulinomaincidence, recurrence, and longterm survival of patients: a 60-year study. Mayo Clin Proc. 1991 ;66:711-719

16. Prevention of blindness from the diabetes mellitus. Report of a WHO consultation

17. Frier BM. The incidence and impact of hypoglycemia in type 1 and type 2 diabetes. Int Diabetes Monit 2009;21:2108

18. King P Kong M, Parkin H, MacDonald I, Tattersall R. well-being, cerebral function, and physical fatigue after nocturnal hypoglycemia in IDDM. Diabetes care 1998;21:341-5

19. Association AD. 8. Pharmacologic Approaches to Glycemic treatment: Standards of Medical Care in Diabetes2018 Diabetes care 2018; 41 :S73-S85

20. Helms K Kelley K. Drug -Induced Hypoglycemia. Hypoglycemia-cause and Occurences: InTech: 2011. 